\title{
Otto Warburg's first approach to photosynthesis
}

\author{
Kärin Nickelsen
}

Received: 25 December 2006/Accepted: 24 March 2007/Published online: 29 June 2007

(C) Springer Science+Business Media B.V. 2007

\begin{abstract}
In the field of photosynthesis research, Otto Warburg (1883-1970) is predominantly known for the role he played in the controversy that began in the late 1930s regarding the maximum quantum yield of photosynthesis, even though by that time he had already been working on the topic for more than a decade. One of Warburg's first contributions on the subject, which dates from around 1920 , is his proposal for a detailed model of photosynthesis, which he never completely abandoned, despite later overwhelming evidence in favor of alternatives. This paper presents a textual and graphical reconstruction of Warburg's model and of his argument for its validity. Neither has received much attention in the history of science, even though the model was certainly one of the most plausible explanations of the period and therefore could not be so easily discredited.
\end{abstract}

Keywords Otto Warburg · History of photosynthesis research $\cdot$ Models of photosynthesis

\section{Introduction}

Nobel Laureate Otto Warburg (1883-1970; see Fig. 1 for a photograph) is well known in the field of photosynthesis research: he is predominantly famous-or rather, notorious-for his influence on the long-running debate on the maximum quantum yield of photosynthesis, and for his stubbornness in holding to his own particular concept of photosynthesis, even after overwhelming evidence had

K. Nickelsen ( $\square)$

History and Philosophy of Science, Institute of Philosophy, University of Bern, Sidlerstrasse 5, 3012 Bern, Switzerland e-mail: nickelsen@philo.unibe.ch been established in favor of alternatives. ${ }^{1}$ In the $1940 \mathrm{~s}$ and the 1950s, when the controversy was at its height, Warburg had already been working on this topic for more than 30 years; yet, his earlier work in photosynthesis has received little attention, even though Warburg introduced his manometric methods, which would greatly influence the whole field, in his first paper on the subject in 1919. In this paper he also interpreted for the first time the 1905 findings of Frederick F. Blackman (1866-1947) and Gabrielle L. C. Matthaei-regarding the unusual shape of the $\mathrm{CO}_{2}$ and light curves, published in Blackman (1905), Matthaei (1905), and Blackman and Matthaei (1905)—as a series of two different reactions and tried to make sense of this result in a detailed hypothesis on the mechanism of photosynthesis. This was quite a challenge at the time, since all that was known of a biochemical process was what went in and what came out. Photosynthesis was basically a black box, the internal mechanism of which was totally obscure. Scientists did their best to shed light on the process, as can be taken from the extensive timeline of discoveries given in Govindjee and Krogmann (2004), but, like other metabolical processes, photosynthesis proved highly sensitive to intervention. As Patricia Craig put it in her history of the Carnegie Institution's Department of Plant Biology: "Whenever the box's cover was pried off, the wheels inside stopped turning." (Craig 2005, p. 125). In this paper, I shall introduce Warburg's early attempts to prise open the black box, based on the

\footnotetext{
${ }^{1}$ The Nobel Prize in Physiology or Medicine was awarded to Warburg in 1931 "for his discovery of the nature and mode of action of the respiratory enzyme"; see the information on the official website, http://nobelprize.org. For biographical information on Warburg, see, e.g., Krebs (1972, 1979), Bücher (1983), Höxtermann and Sucker (1989), Werner (1991), Henning (2000), and Höxtermann (2001). On the quantum controversy in particular, see also Govindjee (1999).
} 


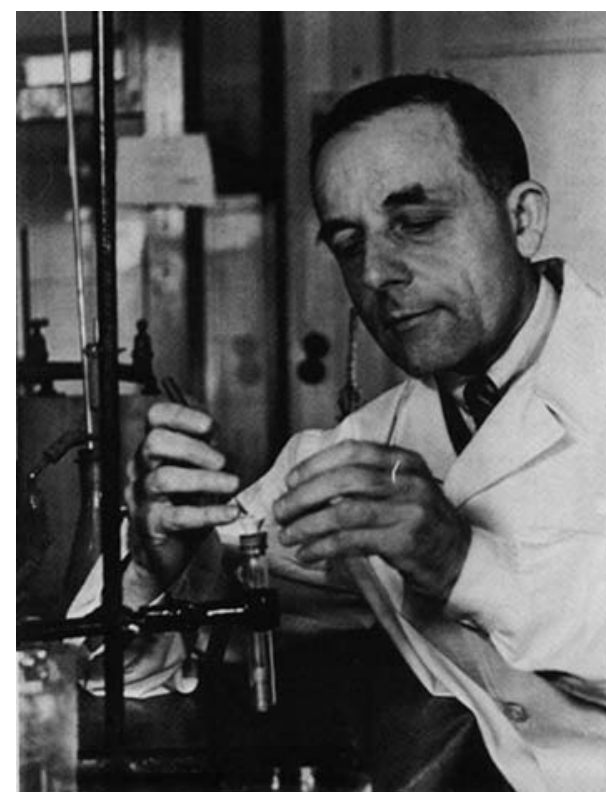

Fig. 1 Otto Heinrich Warburg (1883-1970). Reproduced from Bücher (1983), before the first page of the book

reasoning in his first three articles. I also hope to elucidate the article's own, and from a certain perspective, compelling logic_even if Warburg's approach seems so bizarre from today's viewpoint.

\section{The first series of articles}

Otto Warburg embarked upon the field of photosynthesis research with two closely related articles, published in 1919 and 1920, dealing with the general mechanism of photosynthesis. Both articles were entitled "On the rate of photochemical carbonic acid decomposition" ("Über die Geschwindigkeit der photochemischen Kohlensäurezersetzung"; see Warburg 1919, 1920). In 1921, Warburg additionally gave a much shorter synopsis of his findings in the German journal Die Naturwissenschaften, which included a more comprehensive interpretation (see Warburg 1921). It was only in 1922 that Warburg published his first account of the quantum yield of the process, that is, of the efficiency of photosynthesis (Warburg and Negelein 1922); this was followed in 1923 by a second paper on the influence of the wavelength of light on photosynthetic efficiency, which he co-authored with his long-standing collaborator Erwin Negelein (1897-1979; see Fig. 2); this was published as (Warburg and Negelein 1923).

The tremendous effect of the latter two papers, the content of which led to the later quantum yield controversy, is well known. However, what is less well known are the considerable achievements of the first three papers. Warburg revolutionized the field by introducing a whole

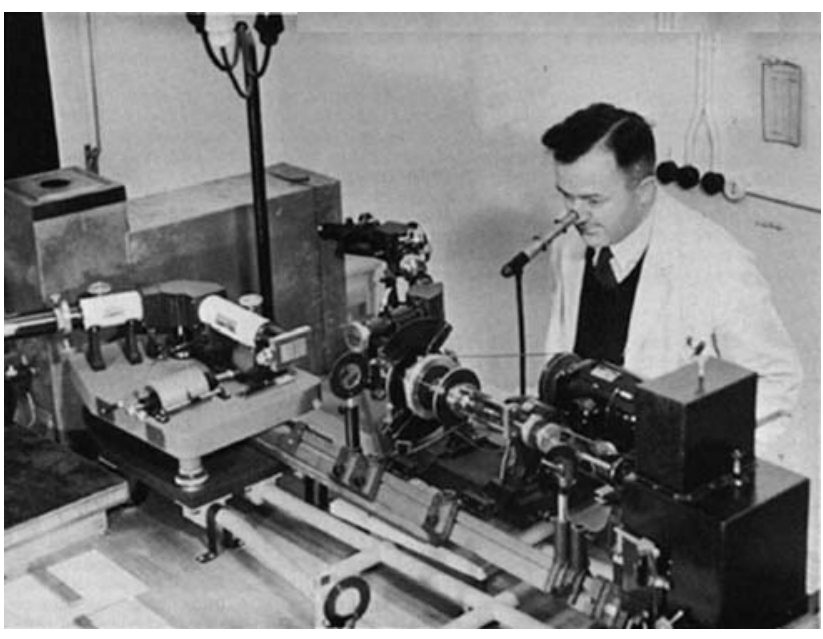

Fig. 2 Erwin Negelein (1897-1979) at the observation telescope of a spectrometer. Reproduced from Bücher (1983), p. 19

series of new techniques that were to become the standard for photosynthesis research up until the 1970s. These included the use of manometric rather than gasometric or titrimetric methods for measuring the rate and progress of photosynthesis (see Fig. 3 for the manometer Warburg used in 1919; also see Fig. 5 in Höxtermann 2007); to this end, Warburg substituted the study of leaves and whole plants with the unicellular green alga Chlorella as the subject of investigation, which to this day remains one of the model organisms for photosynthesis (on green algae as model organisms, see, e.g., Zallen 1993).

The prompt inclusion of Warburg's experimental protocols in contemporary textbooks and manuals reveals how quickly his methods became the accepted standard of the field. In addition to manometry and Chlorella, Warburg

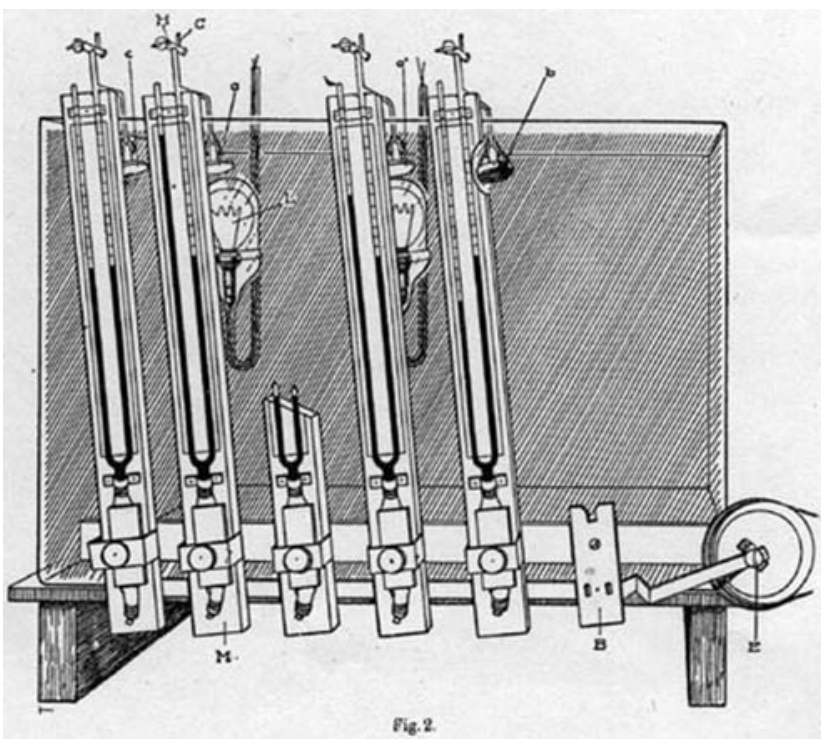

Fig. 3 The apparatus that Warburg used for his first photosynthesis studies. Reproduced from Warburg (1919), p. 245 
applied sophisticated photophysical techniques, such as bolometry, absorption methods, and intermittent illumination by means of rotating sectors. He was also the first person to systematically use inhibitors to discover more about the biochemical process of photosynthesis. Warburg had first developed this approach, together with the general application of manometric techniques and the use of unicellular research objects (sea urchin eggs, blood cells), during his earlier work on cell respiration; he then applied these methods analogously-and equally successfully-to his photosynthesis studies (Höxtermann and Sucker 1989, 59f.). From the results of his research, Warburg finally proposed a mechanism that involved the formation of a "photolyte," a concept that he adopted from contemporary physics-indeed, it was his father, Emil, who introduced this concept to science in 1917 (see Warburg 1917). (For further discussion on photolyte, see Höxtermann 2007.)

In this paper, I shall concentrate on the new model of the photosynthetic process put forward by Otto Warburg in his first three articles (Warburg 1919, 1920, 1921). Since Warburg did not present his line of argument in either one of them comprehensively, I shall not trace each article in detail but will summarize the main elements of their content systematically. ${ }^{2}$

\section{Survey}

The question that interested Warburg in 1919 was not which factors enabled the formation of oxygen or the process of photosynthesis in general, as one might have expected, but why carbonic acid (formed when carbon dioxide combines with water) can, under normal circumstances, be decomposed in green plant cells. ${ }^{3}$ Warburg was not questioning the fact that carbonic acid was being decomposed. Since according to the summary equation for photosynthesis, the quantities of the two substances were stoichiometrically equivalent, that is, as many carbonic acid molecules were consumed as oxygen molecules produced, this assumption seemed to be almost too obvious and was rarely seriously questioned (although, of course, we know today that history would prove it wrong). However, the question was how carbonic acid and other substances that take part in the photosynthetic processes

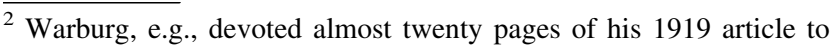
describing his new techniques in detail: the growing of the algae, his light source, his manometric methods, the apparatus, and specific vessels, and, finally, the use of rotating sectors to expose the algae to alternating light and dark conditions. Although this section is interesting in its own right, it is not immediately relevant to this paper, so I have chosen to skip over most of it.

${ }^{3}$ Assuming the participation of carbonic acid in the process rather than carbon dioxide was common practice at the time.
}

were rendered reactive, since outside the living cells all of them were known to be highly inert.

Warburg's answer was, in short, that this reactivity was achieved by the adsorption of the participating substances to internal cell surfaces containing heavy metals. Therefore, destroying these surfaces meant destroying the sites of reaction and, hence, inhibiting photosynthesis (Warburg 1921, p. 354). This corresponds exactly to Warburg's interpretation of the process of cell respiration, arrived at after researching the subject from 1908 to 1914: it is a surface-dependent series of reactions that requires the participation of iron (Warburg 1914; Höxtermann 2001, pp. 265-268; Kohler 1973; also see Höxtermann 2007). Warburg postulated that, in the case of photosynthesis, three different classes of reaction were involved:

(1) A primary photochemical process of light acting on a cell's pigments, the product of which was a reducing agent.

(2) The formation of a carbonic acid derivative through a series of ordinary chemical reactions. This process required the involvement of heavy metals, presumably part of an enzyme, and included the intermediate binding of carbonic acid to components of the cell. Thus, the process was surface dependent.

(3) Secondary reactions of the carbonic acid derivative with the primary photochemical product (PPP), which would eventually lead to the release of oxygen and the synthesis of organic substances. These reactions were also thought to be surface-dependent chemical processes.

In the following sections, I shall present Warburg's main evidence for these hypotheses and the course of his argument.

\section{Experimental findings and their interpretation}

\section{Carbon dioxide concentrations}

Having given a detailed explanation of his new techniques, Warburg started his paper of 1919 by re-examining the standard parameters of photosynthesis. The first topic he looked at again was the relationship between photosynthesis and levels of carbon dioxide concentration, measured at high light intensities. There are no surprises here-Warburg confirmed the findings of Blackman, who in 1905 had established the fundamental Law of Limiting Factors, a restatement of Liebig's Law of the Minimum (Blackman 1905). As Blackman and his collaborators had demonstrated, at low carbon dioxide concentrations the rate of photosynthesis increased in proportion to a rise in carbon dioxide concentrations. However, after a certain point, 
additional increases in carbon dioxide concentrations did not promote the rate of photosynthesis so efficiently, until the rate remained constant, notwithstanding any further increases in the gas (Blackman 1905; Matthaei 1905; Blackman and Matthaei 1905). Like Blackman before him, Warburg concluded that, while in the first part of the curve carbon dioxide concentrations limited the rate of the process, in the second part of the curve some other limiting factor must have been present.

Warburg gave the topic a new turn by proposing that, since light intensity and temperature were chosen favorably, the limiting factor in the second part of the curve had to be an additional substance, $\mathrm{X}$, which would react with carbonic acid in the course of photosynthesis (Warburg 1919 , p. 253). This substance $X$ might possibly be a component of the green cells, Warburg hypothesized, alluding to Richard Willstätter's (1872-1942) discovery of the occurrence of this type of reaction. Carbonic acid would react with this substance $\mathrm{X}$ to make an unknown derivative, and only then could further reaction steps occur leading to the release of oxygen. Figure 4 gives a graphical reconstruction of the sequence of events proposed by Warburg. ${ }^{4}$

\section{Light intensity}

The second issue Warburg reconsidered was the relationship between photosynthesis and light intensity, measured at high carbon dioxide concentrations, which had also been raised before by Blackman. In agreement with earlier studies, at low light intensities, the rate of photosynthesis increased in proportion to the light, while this effect became less prominent at higher light intensities. After a certain point, the rate of photosynthesis reached a plateau and additional increases in light intensity were unable to promote the process any further. Again, the phenomenon itself was well known (although Warburg's new technique produced a slightly different curve), but Warburg proposed his own interpretation, at the same time underlining the similarity of this effect to the one described earlier in the paper:

The appearance of the curve is very similar to the one that demonstrates the influence of different carbonic acid concentrations at constant light intensity; the "concentration of light energy" operates in this case like the concentration of a chemical substance. This concordance suggests that each light intensity corresponds to a specific concentration of a primary photochemical product, which, according to its

\footnotetext{
${ }^{4}$ For a detailed introduction to the representation of causal processes in graph form, see: Baumgartner and Grasshoff (2004; Chapter III).
}

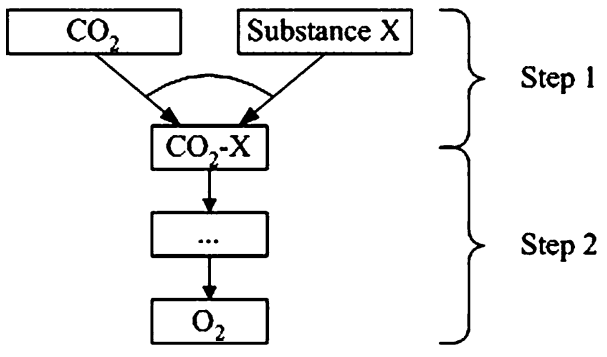

Fig. 4 Reconstructed model of Warburg's interpretation of the carbon dioxide curve. In the first part of the curve, $\mathrm{CO}_{2}$ itself would be limiting the process, while a second substance, $\mathrm{X}$, was thought to be the limiting factor in the second part of the curve, so that no additional increase in carbon dioxide concentrations would be able to promote the formation of oxygen any further. The formed complex of carbon dioxide and substance X (the "carbonic acid derivative") was assumed to undergo further reaction steps before oxygen could be released

concentration, would, in turn, be effective in a chemical reaction. The explanation of the shape of this curve would then have to be similar to the earlier one, by assuming that the rate of assimilation is in proportion to the concentration of the primary photochemical product [PPP] and the concentration of a second substance, which reacts with this primary photochemical product (Warburg 1919, pp. 257f.).

Warburg considered that the light curve also resulted from two different factors that influenced the rate of photosynthesis under different light conditions. Indeed, this time Warburg went even further, since he not only proposed two different factors but also two different reactions that would limit the whole process at low or high light intensities. This was the first time that the shape of this curve, well known since the time of Blackman, had been explicitly interpreted in this way. If one follows Warburg's argument, a series of at least three reaction steps emerge (see Fig. 5): in the first stage light reacts with some other substance, $\mathrm{Z}$, to form the PPP, which in the second stage reacts with another substance, $\mathrm{Y}$, to further the process, before oxygen is released in the third stage.

\section{Temperature}

Warburg also re-examined temperature, the third classic parameter of photosynthesis. At high concentrations of carbonic acid and high light intensities, Warburg found, at the standard temperature interval between $15^{\circ} \mathrm{C}$ and $25^{\circ} \mathrm{C}$, a temperature coefficient of about 2 , in agreement with the literature (that is, with a rise in temperature of $10^{\circ} \mathrm{C}$ the reaction rate doubled; Warburg 1919, p. 258). This indicated that under these conditions a thermochemical process was limiting the assimilation rate. At low carbonic acid concentrations and high light intensities, Warburg found 


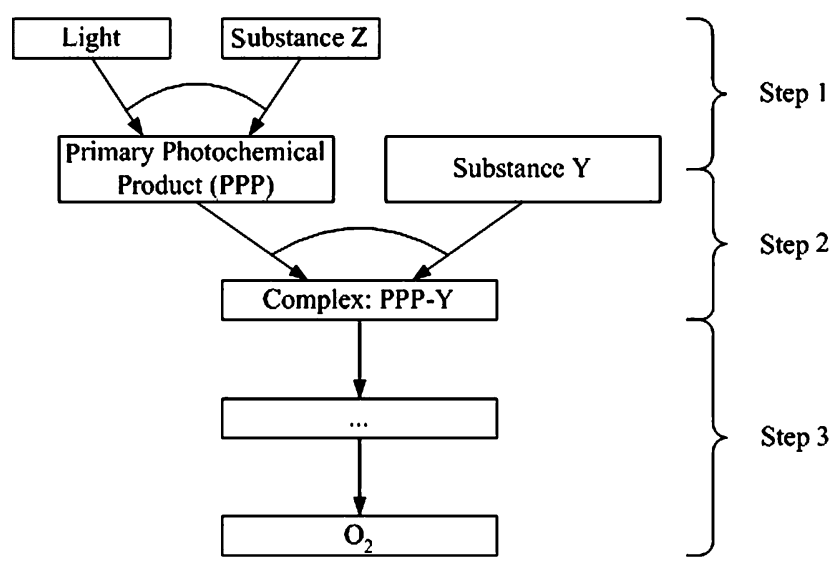

Fig. 5 Reconstructed model of Warburg's interpretation of the light curve. The first step consists of a primary photochemical reaction of light with substance $\mathrm{Z}$, resulting in the primary photochemical product (PPP; Step 1). This product immediately undergoes a reaction with a second substance, $\mathrm{Y}$, and a complex of PPP and Y is formed (PPP-Y; Step 2), which is then subject to further reaction steps leading to the release of oxygen (Step 3)

coefficients of 4-5, that is, an even stronger dependence on temperature; again, a thermochemical reaction was, presumably, limiting here-this, too, was not a new finding. And, finally, at low light intensities, Warburg confirmed "Blackman's important discovery," as he called it, of a coefficient approaching unity, which would mean that under these conditions the rate of photosynthesis is governed by a process that is practically temperature independent: a photochemical reaction was the obvious answer (Warburg 1919, p. 259). In his 1921 article, however, Warburg slightly revised this last result by presenting evidence which showed that at low light intensities the coefficient was negative, that is, the rate of the process rose as the temperature decreased. This, Warburg argued, indicated that in this process high energy substances, such as PPP, were the limiting factor (Warburg 1921, p. 355).

\section{Intermittent illumination}

The next subject that Warburg turned to was new: the effect of exposing photosynthesizing cells to alternating dark and light periods. In order to investigate this effect, Warburg used so-called rotating sectors: a disc with one or more sections was placed between the light source and the algae, so that part of the light could be screened off. As Warburg himself explained, in employing this technique he had been inspired by the work of the English plant physiologist Horace Brown (1848-1925) and his collaborator F. Escombe (see Brown and Escombe 1905, p. 38; Warburg acknowledges Brown's work in Warburg 1919, p. 263). However, rotating sectors were also standard instruments in the field of photophysics and, therefore, regularly used in the optical laboratory of the Berlin Physikalisch-Technische Reichsanstalt (PTR), which, at that time, was led by Otto Warburg's father Emil Warburg. So, it was quite natural for Otto Warburg to use-and indeed improve upon-this technique with his own instruments, particularly since many of his photosynthesis experiments of the time - at the very least, his light intensity measurements-were carried out in his father's laboratory (see Warburg 1919, pp. 235, 255). Despite acknowledging Brown's work in general, Warburg vehemently denied the relevance of Brown and Escombe's findings for the interpretation of the actual photosynthesis mechanism, since he maintained that the alleged effects of their findings were artifacts that had occurred as a result of the diffusion of carbon dioxide: like most researchers before Warburg, Brown and Escombe had used whole leaves as objects of investigation, in which the diffusion of gas posed tremendous methodological difficulties; these difficulties, however, were negligible, when one worked with unicellular algae, as Warburg did.

Warburg chose the extent of the sections in such a way that in the course of one rotation half the light would be screened off. Therefore, in two experiments of the same duration, one with rotating sectors, the other without, the former would receive only half the light energy of the latter. Thus, Warburg did not compare the effects of continuous and intermittent illumination with experiments of like duration but with experiments of like light exposure time. In doing so, he found that at high light intensities a certain amount of energy was able to decompose more carbonic acid at intermittent illumination than at continuous illumination. The increase in efficiency depended on the rate of alternation between light and dark periods: at a rate of 8,000 alternations per minute efficiency increased by almost $100 \%$, while at a rate of four alternations per minute an increase of only $10 \%$ was achieved. At low light intensities no differences in efficiency were observed. From these findings, Warburg concluded the following:

If a certain amount of energy, which, when alternated with dark periods of equal length, is $100 \%$ more efficient than the same amount of energy at continuous illumination, we might as well say: in a time interval that is long compared with the length of one period at intermittent or continuous illumination the same amount of carbonic acid is broken down, that is, the average assimilation rate is the same using both types of illumination (Warburg 1919, pp. 262f.)

Warburg proposed two alternative explanations: either decomposition continued to occur during the dark periods at the same rate as before, possibly due to some sort of energy storage; or decomposition was interrupted during dark periods, and then resumed during periods of light at double the rate. Warburg preferred the latter interpretation, 


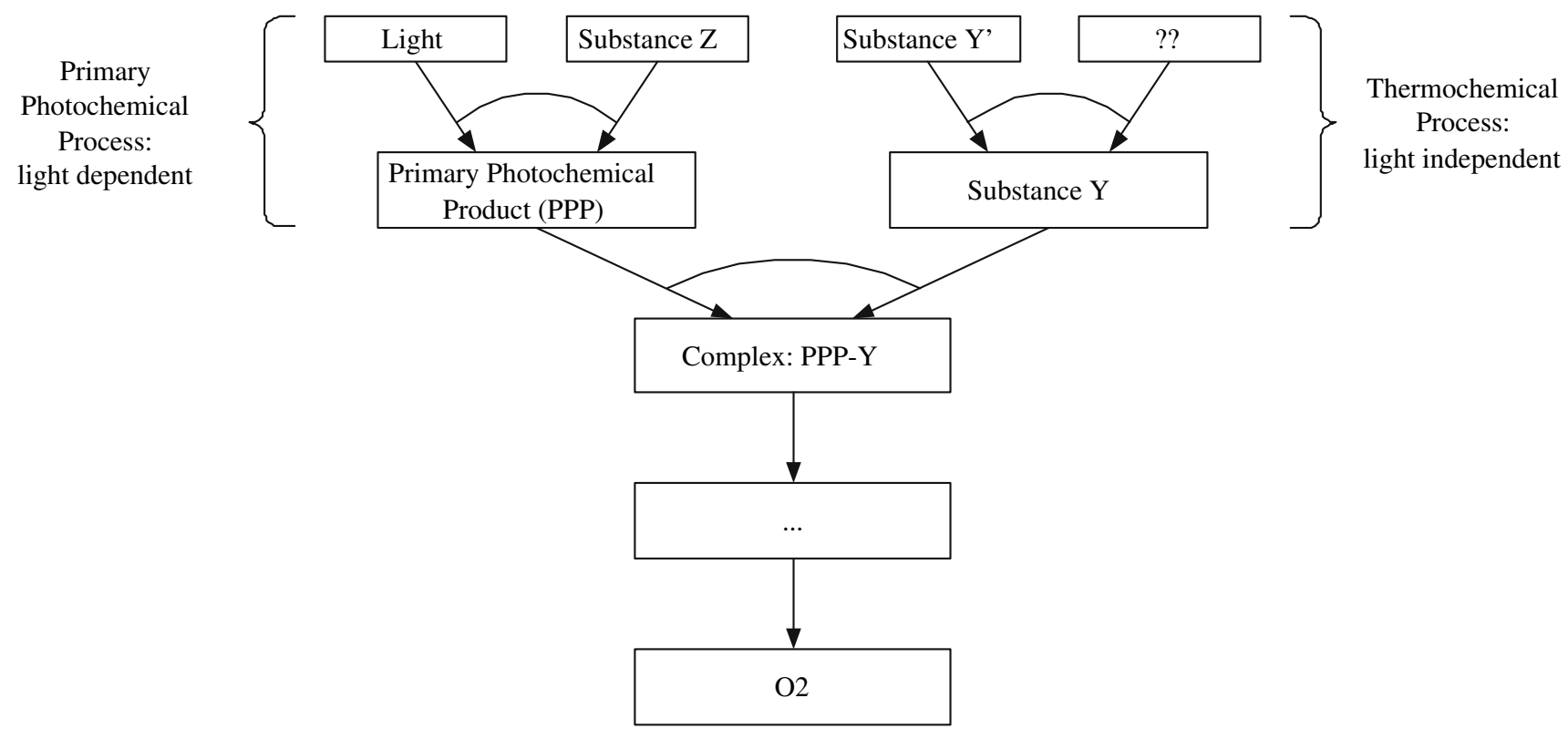

Fig. 6 Expanded model of Warburg's interpretation of the light curve: whereas the PPP is formed during a light-dependent process, the substance $\mathrm{Y}$ is produced during a light-independent series of

and suggested that, while decomposition itself stopped on the interruption of light, other partial processes would continue until an equilibrium state had been reached (which at continuous illumination would never be attained). Warburg further assumed that during these "dark" processes a substance was formed that could be decomposed by light energy. Since after a dark period an increased concentration of decomposable substance would be available, light could act more efficiently under these circumstances - assuming that light of sufficient intensity was available: low light intensities would not be enough to enable proper use of the increased availability of dark period products. This interpretation perfectly matched Warburg's theory on the light intensity curve: the lightdependent reaction-the primary photochemical pro- reactions. The former limits the rate of photosynthesis at low light intensities, the latter at high light intensities

cess-provided only part of the necessary educts for the eventual release of oxygen; the other component was supposed to be an additional substance, Y, which had to react with the PPP (see above and Fig. 7). In addition, Warburg now assumed that this substance $Y$ was derived from a precursor substance, Y', by light-independent chemical reactions. With the resumption of light after a dark period, therefore, the PPP would meet with increased concentrations of $\mathrm{Y}$ and, thus, the process would proceed at a higher rate (see Fig. 6 for the extended model).

\section{Anesthetics}

The effect of inhibiting substances, in particular of anesthetics, on photosynthesis played an important role in
Fig. 7 Reconstruction of Warburg's photosynthesis model

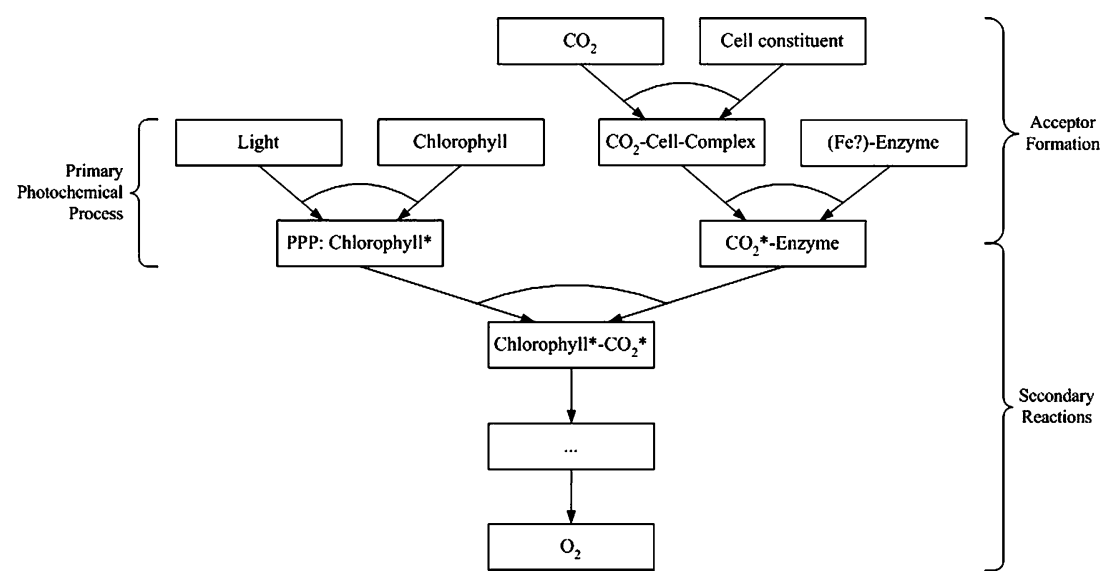


Warburg's reasoning (as previously mentioned, Warburg had taken this approach from his studies in cell respiration). Warburg predominantly investigated the effect of urethanes, in particular phenylurethane. As was well known at the time, photosynthetic assimilation could be reversibly inhibited by these substances. Warburg confirmed this general finding for green algae and concluded that photosynthesis was far more sensitive in this respect than, for example, respiration. He interpreted this finding following the general mechanism of anesthesia, which he had established in earlier research:

Taking into account that the effect of anesthetics is due to changes in the membranes [in German, Warburg used the term "Grenzschichten"] one must conclude that the slightest changes in these layers thus inhibits the process of [photosynthetic] assimilation. This agrees with the experience that, in contrast to other life processes, as, for example, respiration and fermentation, [photosynthetic] assimilation is already suspended at the slightest mechanical interference in the structure of the cell (Warburg 1919, pp. 265f).

The above interpretation matched Warburg's finding that the inhibitory effect of an anesthetic substance was stronger, the higher its adsorptive capacity, that is, its tendency to adhere to surfaces (Warburg 1920, pp. 196f.). Since the inhibitory effects were observed under all circumstances - that is, at low and high light intensities as well as at different carbon dioxide concentrations. Warburg concluded that all the reactions that limited the rate of the process under different conditions were surface dependent. The sensitivity of photosynthesis to anesthetics at high light intensities and low carbon dioxide concentrations, for example, demonstrated that the limiting process under these conditions (which he considered to be the binding of carbonic acid to an unknown substance, $\mathrm{X}$ ) was to be seen as a reaction that took place on the cell's internal surfaces, presumably, at the membranes (Warburg 1920, p. 199). The same applied to the limiting process at low light intensities and high carbon dioxide concentrations, which also proved sensitive to anesthetics: according to Warburg, the limiting process under these conditions was the lightdependent stage; however, since light absorption itself was surely not sensitive to anesthetics, Warburg concluded that the limiting process here must also involve a secondary (although indispensable) surface-sensitive reaction (Warburg 1919, p. 266). This corresponded well to his assumption of a primary photochemical step-the absorption of light by substance $\mathrm{Z}$-followed by a subsequent interaction of the resulting product with another substance, Y (see Fig. 5).
Hydrocyanic acid

Warburg paid particular attention to the influence of hydrocyanic acid, another substance with inhibitory effects, which had also greatly influenced Warburg's earlier research on cell respiration, as it acted in a fundamentally different way to the urethanes. Warburg demonstrated that already at very low concentrations of this substance-such as by an N/10,000 hydrocyanic acid solution-assimilation was reversibly inhibited (Warburg 1919, p. 266). By contrast, respiration was not even inhibited by an N/100 solution of hydrocyanic acid, that is, at a 100-fold higher concentration. However, this strong inhibition of photosynthesis could only be observed at high light intensities, whereas at low light intensities it was far less obvious. Thus, Warburg concluded that the limiting process at high light intensities was sensitive to hydrocyanic acid, while the limiting process at low light intensities was not (Warburg 1919, p. 266).

In order to explain this finding, Warburg introduced the notion of the gas exchange equilibrium, that is, the state of a slightly illuminated cell, in which assimilation or oxygen production and respiration or oxygen consumption equal each other; consequently, at this point no gas exchange is measurable. Today this is known as the compensation point of photosynthesis. Now, when Warburg tested the effects of hydrocyanic acid, he found that, up to that point, oxygen production in the course of photosynthesis was being inhibited in proportion to the concentration of hydrocyanic acid. However, from the compensation point on, there was no increase in effect on adding any further hydrocyanic acid, which meant, Warburg argued, that the influence of illumination on the respired oxygen was only slightly inhibited, even by large amounts of cyanide (Warburg 1920, p. 199).

He explained this in more detail:

The data listed in Table IXa demonstrate that N/500 hydrocyanic acid solutions completely inhibit the release of oxygen from carbonic acid [in photosynthesis]; even at high light intensities of 19,000 lux, the cell is no longer able to develop any positive pressure. However, a certain [low] amount of illumination will split the respiration products and release oxygen in cells treated with hydrocyanic acid at the same rate as in cells without hydrocyanic acid. Thus high concentrations of hydrocyanic acid have no effect on the photochemical reaction mechanism as can be seen from the effect on the oxygen that was bound in the course of respiration - but they inhibit the ability of carbonic acid to undergo photochemical reactions (Warburg 1920, pp. 203f.). 
Warburg's point was that illuminated cells, under any conditions, would release some oxygen that had not been produced by photosynthesis but by photochemical effects on other substances within the cell-for example, by the effect of light on the products of respiration, which Warburg identified as being mainly, although not exclusively, carbon dioxide. Since this photochemical splitting of molecules still went on even at high concentrations of hydrocyanic acid, Warburg argued that the inhibitory effect of this substance on assimilation had to be due to the blocking of other processes. Warburg, thus, suggested that hydrocyanic acid inhibited the ability of carbonic acid "to undergo photochemical reactions" (see quotation above). This corresponded to Warburg's assumption that carbonic acid had to bind to another substance, $\mathrm{X}$, before the resulting derivative could be decomposed. It was exactly this binding process that Warburg thought would be inhibited by hydrocyanic acid; and since it was known from other contexts that (1) hydrocyanic acid mainly acted by inactivating necessary heavy metals and (2) that these heavy metals were usually part of the catalyzing enzyme, Warburg inferred that the reaction in question was an enzyme-catalyzed reaction requiring the involvement of heavy metals.

\section{Photochemical induction}

The next finding, presented in Warburg's second article of 1920, was the phenomenon of "photochemical induction." The principle effect had first been observed in the photochemical reaction between chlorine and hydrogen: if this mixture was irradiated, hydrochloric acid was formed; however, the rate of this reaction was initially slow, gradually accelerating to a constant final value. As Warburg explained, this delay had been shown by Walther Nernst to be primarily due to secondary reactions of this chain reaction process rather than to the primary photochemical reaction (Warburg 1920, p. 189). A similar phenomenon, Warburg argued, could also be observed in photosynthesis, when studied under intermittent illumination:

If one switches to long periods [of darkness and light] and, in addition, prolongs the dark periods in comparison to the light periods, it turns out that a certain amount of radiation, which, when alternated with dark periods, breaks down less carbonic acid than the same amount under continuous illumination (Warburg 1919, pp. 265f.)

Only after some minutes of illumination, Warburg reported, would the usual constant value be reached. As he demonstrated with his data, extending the dark periods by up to 5 min resulted in a decrease in efficiency of the following light period of $70-80 \%$ compared with the efficiency of the same radiation without any dark periods. Thus, Warburg concluded, the assimilation rate after dark periods rose only gradually. In order to be able to measure this increase manometrically, Warburg first exposed his algae to a 5-min dark period; then he had the same algae irradiated for $0.5-3 \mathrm{~min}$. However, since it took some time before newly formed oxygen could be detected by manometric methods, as Warburg explained, he darkened the cells again and only took the reading after some subsequent dark minutes, after a constant value had been reached. Furthermore, Warburg worked with very thick cell suspensions. Using this set-up, he found that at $25^{\circ} \mathrm{C}$ a constant rate of assimilation was only reached after a time lag of $2 \mathrm{~min}$. However, this was only the case at high light intensities, while he could not demonstrate any such delay at low light intensities. In this respect, Warburg's observations differed significantly from the usual induction phenomenon known to photochemistry in general: whereas the induction period of the chlorine-hydrogen reaction was shorter, the higher the light intensity, in photosynthesis Warburg observed the reverse. Thus, Warburg concluded that the explanation for the two phenomena had to be different as well. He suggested the following:

This phenomenon [i.e. the induction period in photosynthesis] cannot be interpreted by assuming that during the dark periods substances accumulate that would immediately react with the oxygen that is formed on illumination, so to say, in statu nascendi; in this case the induction period should be longer, the lower the intensity of illumination, while in actual fact the opposite can be observed. Thus, it rather follows from the observations that 1) no oxygen is released in the course of the primary process and 2) no substances are formed in the course of the primary process that would spontaneously (in dark reactions) give rise to oxygen. [...] Points 1 and 2 are all that can safely be said about the primary process; both make it very unlikely that the primary process concerns the carbonic acid molecule (Warburg 1920, pp. 208f.).

\section{Oxygen}

Warburg finally investigated the influence of different oxygen concentrations on photosynthesis. As was known, for example, from the experiments of Willstätter (cf. Willstätter and Stoll 1918), for photosynthesis to occur a certain minimum level of oxygen needed to be present-according to Willstätter an amount of less than 1/ $1,000 \mathrm{~atm}$. Starting from this, Warburg studied the influence of higher oxygen concentrations (1/50 to $1 \mathrm{~atm})$ at high light intensities and found that under these conditions the photosynthesis rate decreased as oxygen partial 
pressure increased; however, the effect diminished when oxygen partial pressures approached 1 atm.

Warburg considered two possible explanations: either the oxygen would re-oxidize intermediate products of photosynthesis to carbon dioxide, so that, in effect, the end product stage would never be reached; alternatively, the oxygen might compete with the (modified) carbonic acid as an acceptor of the energy transferred by the PPP and, by this means, prevent the process from being completed. Warburg, of course, favored the latter explanation, which would be compatible with his model of the mechanism.

\section{Photosynthesis framed as a photolysis}

As the climax of his second article, Warburg integrated all these findings into a comprehensive interpretation of the mechanism of photosynthesis. In order to do so, he introduced the concept of "photolysis" (the splitting of substances by light), which his father had been the first to use in his studies of photochemistry. The subject of a photolysis was called a "photolyte." Later in his career, Warburg defined this term as a photochemically active substance that is broken down by light (see, e.g., Warburg et al. 1969, p. 961). However, when he first used this term in 1920, he spoke of the whole photosynthetic cell as being a "photolyte" (see, e.g., Warburg 1920, title of section V), that is, here the term photolyte seems to imply the whole system of photolysis. Warburg had clearly not yet arrived at his final view on photosynthesis, as prominently expressed, for example, in Warburg et al. 1969, in which he spoke of the complex of chlorophyll bound to carbonic acid as being "the photolyte" (which, of course, as we know today, is a purely speculative concept without any material correlate; see also Höxtermann and Sucker 1989, pp. 94-99; also see Höxtermann 2007).

In all photolysis reactions, Warburg explained in his 1920 article, one had to distinguish between the primary and secondary processes: while the primary reaction always involves a change in the light absorbing molecule, the secondary reactions takes place between the primary photochemical products or between these and other constituents of the photolyte-understood here as the whole system (Warburg 1920, p. 206). The latter, that is, the constituents of the photolyte that react with PPPs in secondary processes, Warburg called "acceptors," since they were the first to accept the absorbed light energy in the course of a chemical reaction (note that this differs significantly from our present understanding of electron or hydrogen "acceptors" in photosynthesis; only the expression is the same, not the meaning). However, photosynthesis, Warburg emphasized, was not a simple photolysis of carbonic acid but a rather more complicated process:
The primary photochemical process, in which oxygen is not released, affects the chlorophyll molecule and leads to the formation of the primary photochemical product. The rate of the formation of the primary photochemical product is in proportion to the amount of radiation absorbed per time unit. The concentration of the primary photochemical product is determined both by the rates of its formation and its consumption. The primary photochemical product reacts in secondary reactions with the acceptor.

The acceptor is not carbonic acid but a derivative of carbonic acid, which is formed in the cell by a chain of chemical reactions. Thus, there is a third class of reactions in the cell, in addition to the primary photochemical process and the secondary reactions: namely, acceptor formation. Acceptor formation is a sequence of spontaneous reactions that without illumination would quickly come to rest, due to the accumulation of end products. On illumination, however, the end products - the acceptors - are consumed during the secondary reaction: a process which destabilizes the dark equilibrium.

Both the reactions that lead to the formation of the acceptor and the reaction between the acceptor and the primary photochemical product are surface-dependent and, thus, the way they function is extremely sensitive to changes in the surface environment.

In contrast to the secondary reaction, the formation of the acceptor is inhibited by small amounts of hydrocyanic acid. Since the effect of hydrocyanic acid probably consists of the transformation of heavy metals from an active form into an inactive complex compound, one should consider the involvement of heavy metals in the process of acceptor formation (Warburg 1920, pp. 206f.).

The above was the core of Warburg's photosynthesis model, although he made some additions to this notion of photosynthesis in 1921. The full sequence of reactions, as Warburg conceptualized them in 1921, is reconstructed in Fig. 7 in the form of a scheme. In order to clarify matters, I shall briefly comment on Warburg's own statement and summarize the additions, both with reference to Fig. 7 .

The primary process, according to Warburg, was the most elusive reaction of the whole mechanism of photosynthesis. Nothing much could be said about it; the only safe conclusions Warburg felt entitled to draw were that this process did not yet give rise to oxygen; and that it involved a change in a light-absorbing molecule. In his 1920 article, Warburg identified this molecule as chlorophyll (see quotation above), while in 1921, he wrote more carefully about the cell's pigments in general, that is, the two kinds of chlorophyll ( $a$ and $b$ ), the xanthophyll and 
the carotenes (Warburg 1921, p. 354; for simplification purposes, only chlorophyll is mentioned in the figure). On absorbing light energy, the short-lived PPP is formed, which in 1921 Warburg assumed it to be "isomers of these [light absorbing] pigments, enriched in energy by $v$ " (Warburg 1921, p. 354; German original: ,um h $v$ energiereichere Isomere dieser Farbstoffe"). The higher energy level of chlorophyll in this activated state is indicated in the figure by an asterisk $(*)$.

At the same time, Warburg also held that a second sequence of purely chemical reactions was necessary as a prerequisite for photosynthesis to continue to occur: acceptor formation, as he called it (but note, again, that the current usage of "acceptor" does not correspond to Warburg's notion of the term). Due to this chain of reactions, Warburg argued, photosynthesis was highly temperature dependent at high light intensities, that is, when there was plenty of light energy available. In his 1921 article, Warburg used, for the first time, the term "Blackman reaction" for the process limiting photosynthesis under these conditions (Warburg 1921, p. 355). According to Warburg, it was this class of reactions that made carbonic acid susceptible to cleavage, by forming an activated carbonic acid derivative. The full chain of reactions was yet unknown, but Warburg considered that at least two steps were necessary: the intermediate binding of carbonic acid to some cell constituent and, subsequently, a reaction step that somehow modified the bound carbonic acid. Since the whole process proved highly sensitive to hydrocyanic acid, Warburg assumed, for the second step, the involvement of a heavy-metal (presumably iron) containing enzyme that formed a complex with carbonic acid and transformed it into its activated derivative-again, the activation is indicated in Fig. 7 by an asterisk (*). This process was also shown to be surface dependent by its high sensitivity to anesthetics. In short, acceptor formation in Warburg's model was thought to be an iron-enzyme catalysis that occurred on internal surfaces (most probably, membranes), the end product of which was a reactive carbonic acid derivative.

Finally, the PPP and the acceptor-that is, the activated pigment and the carbonic acid derivative-were assumed to interact with each other in secondary reactions: the photochemical acceptor was reduced by the reducing agent, that is, the carbonic acid derivative was reduced by lightactivated pigments. Warburg did not go into much detail here, apart from characterizing these reactions, again as surface-dependent purely chemical processes. This was inferred from the fact that even at low light intensities, when assimilation still could be increased in proportion to light intensity, the process was sensitive to surface-active substances, which, Warburg argued, could not be ascribed to light absorption processes alone. Thus, in addition to light absorption, secondary chemical reactions were also limiting the rate of photosynthesis at low light intensities, while at high light intensities the Blackman reaction, that is, acceptor formation, was thought to be the limiting factor. To sum up, Warburg concluded:

This view [of the process of photosynthesis] makes it clear that [photosynthetic] assimilation at low and high intensities of illumination can be influenced in different ways; since in the former case, the secondary reaction would be the limiting process, in the latter case the acceptor formation (Warburg 1920, pp. 212f.).

\section{Conclusions}

Although, in the next few decades, Warburg felt compelled to revise certain aspects of his model, following, for example, some of Willstätter's new findings and other developments in the field, he never completely abandoned it. However, his own experimental focus shifted from these very general topics to the more specialized question of the maximum quantum yield of photosynthesis, since this seemed at the time to be the most promising approach to discovering more about the mechanism. Radioactive tracer molecules would not be available until after 1945 (and even then, Warburg never did believe in their significance for establishing intermediate reaction steps), so he had to rely on other means to arrive at more or less well-founded conclusions.

Soon enough though, Warburg's model proved incompatible with the wealth of new details emerging from laboratories around the world, particularly during the 1950s. However, it is always easier to discredit earlier interpretations with hindsight and accuse historical players of being blind to the obvious. Today, we can easily detect the mistakes and misconceptions of Warburg's model.

One of the obvious dead ends of Warburg's theory was the "photolyte," although Warburg refused to accept any criticism of this concept. In actual fact, Warburg's photolyte-conceived of as the complex of chlorophyll and a carbonic acid derivative-closely resembled the central element of Willstätter's proposal for the process of photosynthesis. In 1918, Willstätter and his long-standing collaborator Arthur Stoll (1887-1971) had published a seminal monograph on photosynthetic assimilation-one of the few extensive treatments of the topic that was available at the time (Willstätter and Stoll 1918). In this book, the authors suggested that a carbon dioxide derivative would, with chlorophyll, form an additive compound of the bicarbonate type. This is very similar to Warburg's photolyte, and it is an obvious assumption that Warburg 
was inspired by the Willstätter and Stoll monograph, in addition to borrowing elements of his father's work and of his own work on cell respiration. Thus, Warburg's photosynthesis model exhibits the traits of a typical "building block strategy," that is, elements of experimental methods and interpretative approaches from various sources were recombined in a new and innovative fashion.

What alternatives were on offer at the time? At the beginning of the twentieth century, the main suggestions for the mechanism of photosynthesis were approaches that were ultimately based either on Justus Liebig's (18031873) organic acid hypothesis, which assumed that carbon dioxide was reduced stepwise via the stages of, for example, citric, tartaric or malic acids (first published in Liebig 1843) or on Adolf von Baeyer's (1835-1917) formaldehyde hypothesis, which assumed that carbon dioxide was reduced in only one reduction step, directly to the formaldehyde stage (Baeyer 1870). ${ }^{5}$ Both theories were highly speculative in parts and mainly constructed on analogous reasoning. An additional drawback of the organic acid hypothesis was that the acid content of plants did not correlate with photosynthesis activity, which would be expected if these acids were intermediates on the pathway to carbohydrates; the main shortcoming of the formaldehyde hypothesis, on the other hand, was that, despite meticulously carried out experiments, no one had ever been able to provide convincing proof of the existence of formaldehyde - a potent cell poison-in green plant cells (e.g. Rabinowitch 1945, pp. 255-260). Nonetheless, while their supporters were unable to produce conclusive experimental evidence in favor of either of these two theories (or any one of the various hybrid approaches) until well into the 1920s, adversaries were equally unable to prove them wrong.

Warburg's work, by contrast, had the definite advantage-and was almost unique at the time in this respect-in that he based all the elements of his photosynthesis model on experimental data, which, moreover, were gathered from living cells under physiological conditions. Most of his contemporaries, with the (partial) exception of Willstätter and Stoll, tried to infer the biochemical mechanisms of photosynthesis from data that had been collected in artificial, non-physiological systems, for example, under high atmospheric pressure, in conditions of extremely high temperatures or strong acidity (Florkin 1977). Warburg was also able to integrate convincingly the findings of the plant physiologists Blackman and Matthaei into his mechanistic model, which most other researchers simply

\footnotetext{
${ }^{5}$ On von Baeyer, see also Florkin (1977), pp. 147-151. Contemporary surveys of the field are provided by Schroeder (1917) and Stiles (1925); for a comparison of Liebig and von Baeyer, see also Rabinowitch (1945), pp. 146-148.
}

ignored (on the long-standing contention between organic chemists, or later biochemists, and plant physiologists, see, e.g., Werner and Holmes 2002).

Thus, discarding Warburg's model from the state of the art of the 1920s would not have been an easy task, closely tied as it was to experimental data and the period's generally accepted knowledge of plant physiology. Despite its shortcomings, then, Warburg's photosynthesis model, which made use of the photophysical concept of photolysis, was unquestionably one of the most plausible explanations of the time.

In the following paper, Ekkehard Höxtermann (2007) has provided an understanding of the background of Warburg's early research and ideas of the others that preceded the work of Warburg discussed in this paper.

Acknowledgments I thank Govindjee (Urbana, Illinois) for inviting me to write this paper and for suggestions during the various stages of this paper. I also thank the three referees for their helpful comments on earlier drafts of this paper; Johannes Sander (Bern), who prepared the graphs; Margareta Simons (Bern), who greatly improved the English of this paper; and Gerd Grasshoff (Bern) for his generous support of the project.

\section{References}

Baumgartner M, Grasshoff G (2004) Kausalität und Kausales Schliessen. Bern Studies in the History and Philosophy of Science, Bern

Blackman FF (1905) Optima and limiting factors. Ann Bot 19:281295

Blackman FF, Matthaei GLC (1905) Experimental researches in vegetable assimilation and respiration. IV. - A quantitative study of carbon-dioxide assimilation and leaf-temperature in natural illumination. Proc R Soc Lond Series B 76(511):402-460

Brown HT, Escombe F (1905) Researches on some of the physiological processes of green leaves, with special reference to the interchange of energy between the leaf and its surroundings. Proc R Soc Lond Series B 76(507):29-111

Bücher T (1983) Otto Warburg. A personal recollection. In: Sund H, Ullrich V (eds) Biological oxidations. Springer, Berlin, pp 1-29

Craig P (2005) Centennial history of the Carnegie Institution of Washington, vol IV: The Department of Plant Biology. CambridgeUniversity Press, Cambridge

Florkin M (1977) A history of biochemistry. Part IV: early studies on biosynthesis. Comprehensive biochemistry, vol 32. Elsevier, Amsterdam

Govindjee (1999) On the requirement of minimum number four versus eight quanta of light for the evolution of one molecule of oxygen in photosynthesis: a historical note. Photosynth Res 59:249-254

Govindjee, Krogmann D (2004) Discoveries in oxygenic photosynthesis (1727-2003): a perspective. Photosynth Res 80:15-27

Henning E (2000) Otto Heinrich Warburg - Der „Kaiser von Dahlem". Beitr Wiss Dahlems 13:91-110

Höxtermann E (2001) Otto Heinrich Warburg (1882-1970). In: Jahn I, Schmitt M (eds) Darwin \& Co. Eine Geschichte der Biologie in Portraits, vol 2. Beck, München, pp 251-274

Höxtermann E (2007) A comment on Warburg's early understanding of biocatalysis. Photosynth Res doi: 10.1007/s11120-007-9164-2 
Höxtermann E, Sucker U (1989) Otto Warburg. Teubner, Leipzig

Kohler RE (1973) The background of Otto Warburg's conception of the 'Atmungsferment'. J Hist Biol 6:171-192

Krebs H (1972) Otto Heinrich Warburg 1883-1970. Biogr Mem Fellows R Soc 18:629-699

Krebs H (1979) Otto Warburg: Zellphysiologe, Biochemiker, Mediziner 1883-1970. Wiss Verlagsgesellschaft, Stuttgart

Liebig J (1843) Die Wechselwirthschaft. Ann Chem Pharm 46:58-97

Matthaei GLC (1905) Experimental researches in vegetable assimilation and respiration. III. - On the effect of temperature on carbon-dioxide assimilation. Phil Trans Series B 197:47-105

Rabinowitch EI (1945) Photosynthesis and related processes, vol 1. Interscience, New York

Schroeder H (1917) Die Hypothesen über die chemischen Vorgänge bei der Kohlensäure-Assimilation und ihre Grundlagen. Fischer, Jena

Stiles W (1925) Photosynthesis: the assimilation of carbon by green plants. Longmans/Green, London

von Baeyer A (1870) Über die Wasserentziehung und ihre Bedeutung für das Pflanzenleben und die Gährung. Ber Deuts Chem Ges Berlin 3:63-75

Warburg O (1914) Über die Rolle des Eisens in der Atmung des Seeigeleis nebst Bemerkungen über einige durch Eisen beschleunigte Reaktionen. Hoppe-Seyler's Zeit Physiol Chem 92:231-256

Warburg E (1917) Über die Anwendung der Quantenhypothese auf die Photochemie. Die Naturwiss 5(30):489-494
Warburg O (1919) Über die Geschwindigkeit der photochemischen Kohlensäurezersetzung in lebenden Zellen. Biochem Zeit 100:230-270

Warburg O (1920) Über die Geschwindigkeit der photochemischen Kohlensäurezersetzung in lebenden Zellen II. Biochem Zeit 103:188-217

Warburg O (1921) Theorie der Kohlensäureassimilation. Die Naturwiss 9:354-358

Warburg O, Negelein E (1922) Über den Energieumsatz bei der Kohlensäureassimilation. Zeit Physik Chem 102:235-266

Warburg O, Negelein E (1923) Über den Einfluss der Wellenlänge auf den Energieumsatz bei der Kohlensäureassimilation. Zeit Physik Chem 106:191-218

Warburg O, Krippahl G, Lehman A (1969) Chlorophyll catalysis and Einstein's law of photochemical equivalence in photosynthesis. Am J Bot 56:961-971

Werner P (1991) Ein Genie irrt seltener. Otto Heinrich Warburg, ein Lebensbild in Dokumenten. Akademie Verlag, Berlin

Werner P, Holmes FL (2002) Justus Liebig and the plant physiologists. J Hist Biol 35:421-441

Willstätter R, Stoll A (1918) Untersuchungen über die Assimilation der Kohlensäure. Sieben Abhandlungen. Springer, Berlin

Zallen D (1993) The "light" organism for the job: green algae and photosynthesis research. J Hist Biol 26:269-279 